\title{
The Effect of Prenatal Methamphetamine Exposure on Recognition Memory in Adult Rats
}

\author{
Markéta Fialová ${ }^{1,3}$, Jana Šírová ${ }^{1,3}$, Věra Bubeníková-Valešová1, \\ Romana Šlamberová ${ }^{2}$ \\ ${ }^{1}$ Department of Brain Pathophysiology and Biochemistry, Prague Psychiatric \\ Center, Prague, Czech Republic; \\ ${ }^{2}$ Department of Normal, Pathological, and Clinical Physiology, Third Faculty \\ of Medicine, Charles University in Prague, Prague, Czech Republic; \\ ${ }^{3}$ Third Faculty of Medicine, Charles University in Prague, Prague, Czech Republic \\ Received October 21, 2014; Accepted March 12, 2015.
}

Key words: Methamphetamine - Cognitive function - Memory - Prenatal exposure

\begin{abstract}
The use of methamphetamine (MA) among pregnant women is an increasing world-wide health problem. Prenatal MA exposure may cause changes in foetus but the exact effects have remained unclear. The aim of this study is to present the effect of prenatal MA exposure on recognition memory in adult rats. Adult female Wistar rats were injected daily with D-methamphetamine $\mathrm{HCl}$ (MA; $5 \mathrm{mg} / \mathrm{kg}$, s.c.) during the entire gestation period. Control females were treated with saline in the same regime. Adult male offspring was administrated acutely by MA (1 mg/kg i.p.) or saline 30 minutes before beginning of an experiment. For testing recognition memory two tasks were chosen: Novel Object Recognition Test (NORT) and Object Location Test (OLT). Our results demonstrate that prenatally MA-exposed animals were worse in NORT independently on an acute administration of MA in adulthood. Prenatally MA-exposed rats did not deteriorate in OLT, but after acute administration of MA in adulthood, there was significant
\end{abstract}

This study was supported by grant \# P303/10/0580 from Grant Agency of the Czech Republic, project \# PRVOUK P34, GAUK 545212 and project \# 260168/SVV/2015 from Charles University in Prague, \# CSM7/CRP/2014 from Ministry of Education, Youth and Sports of the Czech Republic.

Mailing Address: Prof. Romana Šlamberová, MD., PhD., Department of Normal, Pathological and Clinical Physiology, Third Faculty of Medicine, Charles University in Prague, Ke Karlovu 4, 12000 Prague 2, Czech Republic; Phone: +420 224902 713; Fax: +420 224902 750; e-mail: rslamber@If3.cuni.cz 
worsening compared to appropriate control. Prenatally saline-exposed offspring did not deteriorate in any test even after acute administration of MA. Our data suggest that prenatal MA exposure in rats cause impairment in recognition memory in adult offspring, but not in spatial memory. In addition, acute administration of MA to controls did not deteriorate either recognition or spatial memory.

\section{Introduction}

Methamphetamine (MA) is one of the top illicit drug threats worldwide. According to a United Nations Office on Drugs and Crime (UNODC) MA was in 2012 the first or second most used illicit drug in 13 of the 15 Asia Pacific countries surveyed and it's abuse increases more than seven-fold since 2008 (Global SMART Programme, 2013). Moreover, MA is still the most often used "hard" drug in the Czech Republic (Mravčík et al., 2013). The fact that the abuse of MA among pregnant women rises worldwide may cause health problems of pregnant women and may result in developmental impairments of their children (Plessinger, 1998). Even though the exact mechanisms of action of amphetamines are still not fully explained, it had been shown that they can cross both placental and bloodbrain barriers (Bubeníková-Valešová et al., 2009). Arising evidence suggests that prenatal MA exposure influences a growth of foetus and may lead to a variety of developmental, behavioural, and neurological abnormalities (Kwiatkowski et al., 2014).

Several studies were conducted using the imaging technologies on mostly school age children, who were prenatally exposed to MA.The results have shown abnormal brain morphology, altered brain metabolism and impaired child executive functioning (Abar et al., 2014). Roussotte et al. (2012) using the functional connectivity MRI (magnetic resonance imaging) found that the functional connectivity in the striatum of children with prenatal MA and/or alcohol exposure is altered that could explain some of the putative motor deficits. Furthermore, Chang et al. (2004) measured regional brain volumes in 13 children with a history of MA exposure in utero. Smaller putamen, globus pallidus and hippocampus were shown in MRI-based morphometry in those children. In addition, also neurocognitive deficits in attention and memory domains were found.

In rats, MA administration in utero have been shown to induce morphological as well as functional changes in developing pups (Vorhees and Acuff-Smith, 1990; Acuff-Smith et al., 1996). Also our previous studies demonstrated that prenatal MA exposure induces changes in the mesolimbic dopaminergic system, which results in changes in behaviour that is associated especially with sensorimotor development (Šlamberová et al., 2006; Bubeníková-Valešová et al., 2009). Furthermore, we demonstrated that prenatally MA-exposed offspring are more sensitive to MA in adulthood (Schutová et al., 2009a, 2013). As matter of cognitive functions, our studies showed that prenatal MA exposure alone does not affect cognitive functions and that MA application in adulthood impairs learning in the Morris 
water maze regardless of prenatal exposure, which did not support the assumption of prenatal sensitization to drugs in adulthood (Schutová et al., 2008, 2009b). On the contrary, studies of others found impairing effects in learning and memory of prenatally MA-exposed adult offspring (Acuff-Smith et al., 1996; Williams et al., 2003; Herring et al., 2008). As the opinions on the sensitization of prenatal MA exposure vary, the present study focused on two aims. (1) Whether the prenatal $M A$ exposure can influence the recognition memory in adult rats in two cognitive tests and (2) whether the acute injection of MA in adulthood can have more serious impact on recognition memory in the offspring of MA-treated mothers.

\section{Methods}

The experiments were approved by the Commission for working with laboratory animals on the Third Faculty of Medicine of Charles University and were conducted in accordance with the Czech Government Requirements under the Policy of Humans Care of Laboratory Animals (No. 246/1992) with subsequent regulations.

Prenatal and postnatal animal care

Adult female and male Wistar rats weighing 250-300 g were delivered by Anlab (Prague, the Czech Republic) from Charles River Laboratories International, Inc. They were housed 4-5 per plastic cage with controlled temperature $\left(20-22^{\circ} \mathrm{C}\right)$ with regular $12 \mathrm{~h}$ light/dark cycle. Animals had free access to food and water. One week later the females were smeared by vaginal lavage to define the phase of their oestrous cycle. Then they were housed with sexually mature males overnight (one pair in each cage). Next day the females were smeared for the presence of sperm and this was counted as gestational day 1 (as described in Šlamberová et al., 2005).

Female Wistar rats were randomly divided to MA-treated and saline-treated groups. On gestational day 1 the injections of MA or saline were administrated subcutaneously (s.c.) and continued daily till the day of delivery (mostly on gestational day 22).

The day of delivery was marked as postnatal day 0 , pups were cross-fostered, all mothers received the same number of pups from each program of the treatment. On postnatal day 21 pups were housed by sex and left undisturbed until adulthood.

\section{Drug treatment in adulthood}

Prenatally MA- (5 mg/kg MA s.c.) and saline-exposed adult male rats (PD 70-90) were administrated acutely with MA (1 mg/kg i.p.) or saline 30 minutes before beginning of an experiment. This interval was chosen based of previous pharmacokinetic studies (Segal and Kuczenski, 2006; Rambousek et al., 2014). Thus, we obtained four experimental groups: prenatally saline-exposed male rats with MA $(S+M A)$ or saline $(S+S)$ treatment in adulthood and prenatally MA-exposed male rats with $M A(M A+M A)$ or saline $(M A+S)$ treatment in adulthood. The number of animals in each group was 10-12. 


\section{Novel Object Recognition Test}

The Novel Object Recognition Test (NORT) measures the exploration of novel versus familiar objects, which is a component of recognition memory and concentration (Ennaceur et al., 1997). The test consists of three parts: habituation, training and testing.

Habituation:Animals were habituated to the empty square opaque arena $(70 \times 70 \times 60 \mathrm{~cm})$ for three days, each day for 20 minutes.

Training: On the fourth day the animal was trained: the rat was placed into the arena for $5 \mathrm{~min}$ to explore two identical objects placed in the arena. After $5 \mathrm{~min}$ the rat was removed and put back into the cage. The testing box and the objects were then cleaned of potential odours by $70 \%$ alcohol.

Testing: In the testing phase, rat was placed to the box, where one of the original object and one new object of similar size, were placed on the same places as during the training. An experienced researcher, blind to pharmacological intervention and to the group of animals measured the time spent exploring of both objects (the familiar and the new one). The following elements of behaviour were considered as the exploration of the subject: sniffing to the object, close circumvention of the object with the sniffing or observation, rearing to the object, with or without sniffing. Calculation of the interest in a new object in the testing phase, which is called the Investigation Ratio (IR) was calculated as the ratio between the time spent by exploration of a new object $\left(T_{\text {new }}\right)$ to the total time spent by exploration of both objects $\left(T_{\text {total }}\right)\left(I R=T_{\text {new }} / T_{\text {total }}\right)$.

\section{Object Location Test}

The Object Location Test (OLT) works on the same rules as NORT and contains the same three parts (habituation, training, testing), also the calculation is identical $\left(I R=T_{\text {new }} / T_{\text {total }}\right)$. The difference is that OLT measures the exploration time of two same objects, but one is placed to a novel location. It assesses especially spatial memory and discrimination (Ennaceur et al., 1997).

\section{Statistical analysis}

Investigation Ratio of testing phase was analysed by two-way ANOVA (factors: prenatal exposure $\times$ adult treatment) in NORT and OLT separately. Bonferroni posthoc test was used to show the differences between groups.

Differences were considered significant if $p<0.05$.

All statistical data in this report are presented as $[F(N-1, n-N)=x x . x x ; p<0.0 x]$, where $\mathrm{F}=$ test criterion of ANOVA, N-1 = degrees of freedom of groups, $n-N=$ degrees of freedom of individual subjects, $\mathrm{p}=$ probability level.

\section{Results}

Novel Object Recognition Test

The data from the testing phase of NORT (Figure 1) showed a main effect of prenatal drug exposure $[F(1,40)=5.26 ; p<0.05]$. Specifically, prenatally MA-exposed adult 


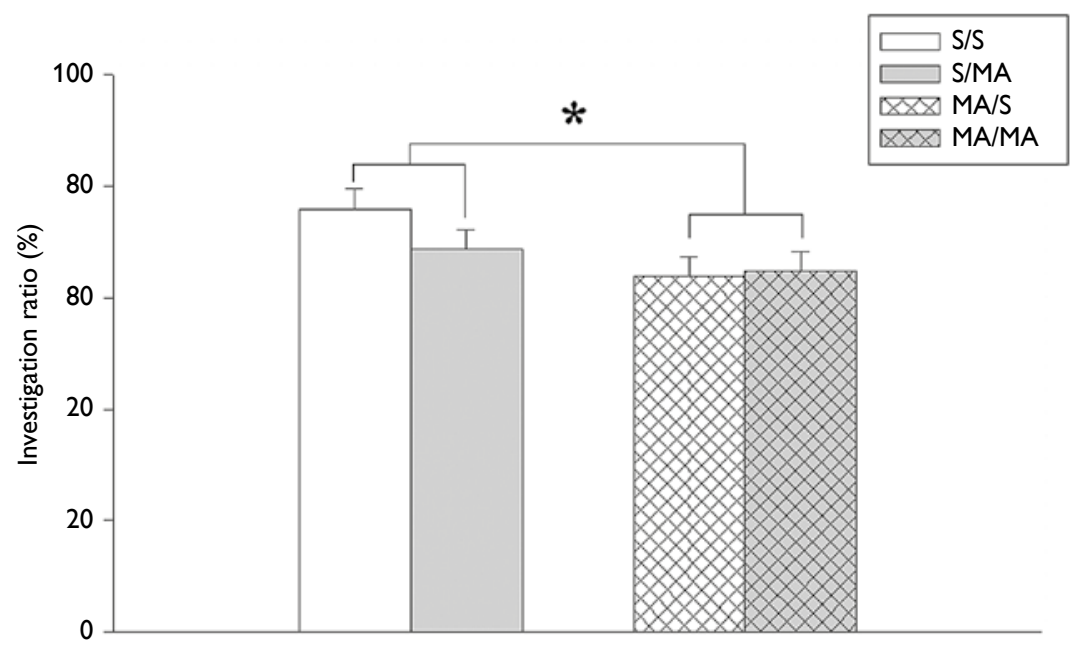

Figure 1 - Performance in Novel Object Recognition Test. The chart shows interest in a new subject in the testing phase, which is called Investigation Ration (IR) in percentage. $S / S=$ prenatally saline-exposed rats treated in adulthood with saline, SIMA = prenatally saline-exposed rats treated in adulthood with $M A$, $M A / S=$ prenatally $M A$-exposed rats treated in adulthood with saline, MAIMA = prenatally MA-exposed rats treated in adulthood with MA. Values are mean \pm SEM $(n=10-12) . * p<0.05=$ main effect of prenatal exposure (prenatal MA < prenatal S).

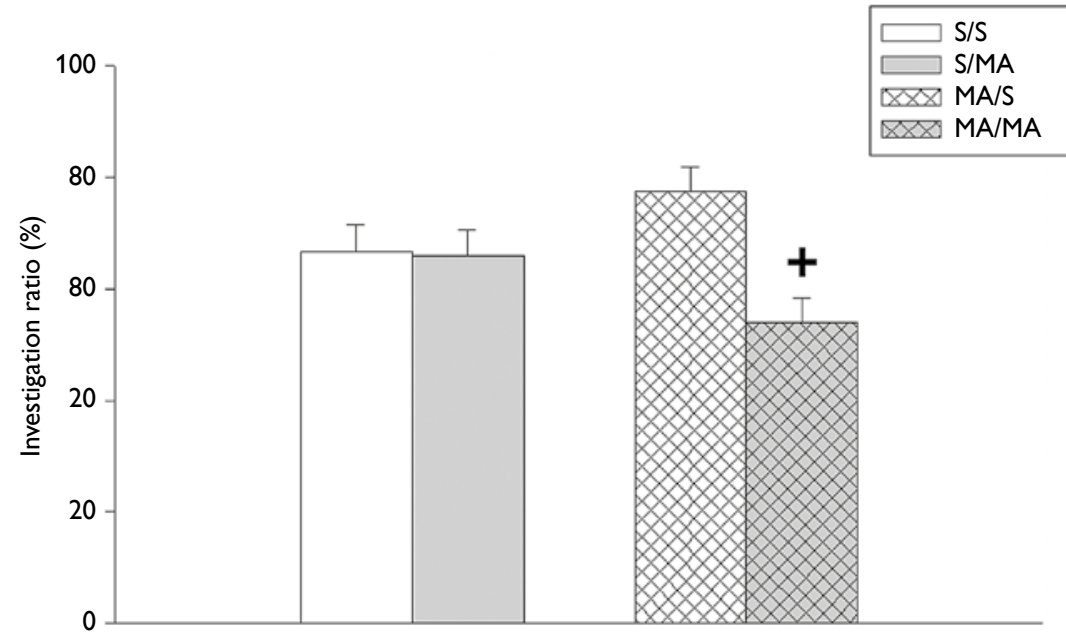

Figure 2 - Performance in Object Location Test. The chart shows interest in a new location in the testing phase, which is called Investigation Ration (IR) in percentage. $S / S=$ prenatally saline-exposed rats treated in adulthood with saline, $S / M A=$ prenatally saline-exposed rats treated in adulthood with $M A, M A / S=$ prenatally MA-exposed rats treated in adulthood with saline, MAIMA = prenatally MA-exposed rats treated in adulthood with MA. Values are mean \pm SEM $(n=10-12) .+p<0.01(M A / M A<M A / S)$. 
male rats were significantly worse in NORT than prenatally saline-exposed ones independently on acute administration of MA in adulthood $(p<0.05)$.

NORT did not show any impact of administration of acute MA on male offspring, neither in the offspring of MA mothers nor in the offspring of saline mothers $[F(1,40)=0.85 ; p=0.36]$.

\section{Object Location Test}

Unlike in NORT, prenatal MA exposure per se did not induce any changes in OLT $[F(1,40)=0.02 ; p=0.89]$. However, there was a main effect of acute drug treatment in the OLT $[F(1,40)=7.37 ; p<0.01]$ and an interaction between prenatal drug exposure and acute adult treatment $[F(1,40)=6.54 ; p<0.05]$. Specifically, our statistical data (Figure 2) showed that acute MA administration induces impairment in memory in prenatally MA-exposed, but not in prenatally saline-exposed adult male rats $(p<0.01)$.

\section{Discussion}

We suggest that prenatal MA exposure in rats cause impairment in recognition memory and inability to concentrate themselves on the task adult offspring. The data from NORT showed significant decrease of ability to recognize the new object in adult Wistar rats, which were prenatally influenced by daily injection of MA.

Surprisingly, the same effect was not supported by the test where the location of the object played a role (OLT). It could indicate that prenatal MA exposure deteriorates only recognition memory, but not the spatial memory. This finding could be endorsed by results of the study of Broadbent et al. (2004) which showed that even though both memories, spatial and recognition, are influenced by the hippocampus, recognition memory does not require as much hippocampal tissue as spatial memory. This fact could lead us to the suggestion that prenatal MA exposure may affect also other brain structures than the hippocampus. Similar results are also demonstrated in the study of Barker and Warburton (2011) showing that hippocampus is crucial for object location, but not for novel object preference task. Studies focused on research of recognition memory assume that participation of the hippocampus, the perirhinal cortex and medial prefrontal cortex are necessary for functioning of recognition memory (Warburton and Brown, 2010). It is possible that MA influences more the perirhinal cortex than the hippocampus. It was proved that MA reduced transporters for serotonin in the perirhinal cortex-prefrontal cortex-hippocampal circuitry and that intact the perirhinal cortex is required for object recognition memory (Reichel et al., 2012). We can assume from our results that prenatal MA exposure can damage the perirhinal cortex and then it leads to impairment of recognition memory.

Interestingly, the acute administration of MA to prenatally saline-exposed offspring did not significantly deteriorate either recognition memory or spatial memory. Similar findings were discovered in many other studies according to the 
critical review by Hart et al. (2012). It seems that acute administration of MA do not impair cognitive functions, but even more it can improve cognitive performance after both intranasal and intravenous doses of MA. The impairing effects of MA on cognitive functions were only found by repetitive administration of larger doses, because it decreases several dopamine markers, including dopamine transporter density (Cadet and Krasnova, 2009).

In contrary, our results showed deterioration especially of spatial memory in offspring, which were prenatally exposed to MA, after acute administration of MA. This could be explained by drug sensitization, which was also demonstrated in our previous studies (Šlamberová et al., 2012, 2013). The prenatal exposure to MA influences dopaminergic function in adulthood. MA affects the dopamine levels in the nucleus accumbens. The basal levels of dopamine is in offspring of MA treated mothers higher by about $300 \%$ and in case of administration of acute dose of MA dopamine levels elevated by about 1,000\%, the difference between MA group and control group was 35\% (Bubeníková-Valešová et al., 2009).

The sensitization to MA in adulthood can also appear as cross-sensitization. According to Wong et al. (2014) methadone used in pregnancy may affect the dopaminergic system and may enhance the possibility of the development of the drug addiction in later life, especially to MA, as was shown in rat model. The other study also found cross-sensitization from buprenorphine to MA in adulthood, again through influence of dopaminergic system and downstream cAMP signalling in the nucleus accumbens (Chiang et al., 2014).

\section{Conclusion}

In conclusion, the present data demonstrate that prenatal MA exposure significantly deteriorates recognition memory and concentration in adulthood, but not the spatial memory. The acute administration of MA to prenatally saline-exposed male rats did not deteriorate cognitive function, while there was a significant worsening after acute administration of MA in offspring prenatally exposed to MA, which could be associated to drug sensitization.

\section{References}

Abar, B., LaGasse, L. L., Wouldes, T., Derauf, C., Newman, E., Shah, R., Smith, L. M., Arria, A. M., Huestis, M. A., DellaGrotta, S., Dansereau, L. M., Wilcox, T., Neal, C. R., Lester, B. M. (2014) Cross-national comparison of prenatal methamphetamine exposure on infant and early child physical growth: A natural experiment. Prev. Sci. 15(5), 767-776.

Acuff-Smith, K. D., Schilling, M. A., Fisher, J. E., Vorhees, C.V. (1996) Stage-specific effects of prenatal d-methamphetamine exposure on behavioral and eye development in rats. Neurotoxicol. Teratol. 18(2), 199-215.

Barker, G. R. I., Warburton, E. C. (2011) When is the hippocampus involved in recognition memory? J. Neurosci. 31(29), 10721-10731.

Broadbent, N. J., Squire, L. R., Clark, R. E. (2004) Spatial memory, recognition memory, and the hippocampus. Proc. Natl. Acad. Sci. U. S. A. 101(40), 14515-14520. 
Bubeníková-Valešová,V., Kačer, P., Syslová, K., Rambousek, L., Janovský, M., Schutová, B., Hrubá, L., Šlamberová, R. (2009) Prenatal methamphetamine exposure affects the mesolimbic dopaminergic system and behavior in adult offspring. Int. J. Dev. Neurosci. 27(6), 525-530.

Cadet, J. L., Krasnova, I. N. (2009) Molecular bases of methamphetamine-induced neurodegeneration. Int. Rev. Neurobiol. 88, 101-119.

Chang, L., Smith, L. M., LoPresti, C., Yonekura, M. L., Kuo, J., Walot, I., Ernst, T. (2004) Smaller subcortical volumes and cognitive deficits in children with prenatal methamphetamine exposure. Psychiatry Res. 132(2), 95-106.

Chiang,Y. C., Hung, T.W., Ho, I. K. (2014) Development of sensitization to methamphetamine in offspring prenatally exposed to morphine, methadone and buprenorphine. Addict. Biol. 19(4), 676-686.

Ennaceur, A., Neave, N., Aggleton, J. P. (1997) Spontaneous object recognition and object location memory in rats: The effects of lesions in the cingulate cortices, the medial prefrontal cortex, the cingulum bundle and the fornix. Exp. Brain Res. 113(3), 509-519.

Global SMART Programme (2013) Patterns and Trends of Amphetamine-type Stimulants and Other Drugs: Challenges for Asia and the Pacific. United Nations Office on Drugs and Crime.

Hart, C. L., Marvin, C. B., Silver, R., Smith, E. E. (2012) Is cognitive functioning impaired in methamphetamine users? A critical review. Neuropsychopharmacology 37(3), 586-608.

Herring, N. R., Schaefer, T. L., Gudelsky, G. A., Vorhees, C.V., Williams, M.T. (2008) Effect of +-methamphetamine on path integration learning, novel object recognition, and neurotoxicity in rats. Psychopharmacology (Berl.) 199(4), 637-650.

Kwiatkowski, M. A., Roos, A., Stein, D. J., Thomas, K. G. F., Donald, K. (2014) Effects of prenatal methamphetamine exposure: A review of cognitive and neuroimaging studies. Metab. Brain Dis. 29(2), 245-254.

Mravčík, V., Chomynová, P., Grohmannová, K., Nečas, V., Grolmusová, L., Kiššová, L., Nechanská, B., Sopko, S., Fidesová, H., Vopravil, J., Jurystová, L. (2013) Výroční zpráva o stavu ve věcech drog v České republice $v$ roce 2012. Available at: http://www.vlada.cz/assets/ppov/protidrogova-politika/vyrocni-zpravy/Vyrocni_ zprava_o_stavu_ve_vecech_drog_v_CR_2012_v2.pdf . (in Czech)

Plessinger, M. A. (1998) Prenatal exposure to amphetamines. Risks and adverse outcomes in pregnancy. Obstet. Gynecol. Clin. North Am. 25(1), 119-138.

Rambousek, L., Kačer, P., Syslová, K., Bumba, J., Bubeníková-Valešová, V., Šlamberová, R. (2014) Sex differences in methamphetamine pharmacokinetics in adult rats and its transfer to pups through the placental membrane and breast milk. Drug Alcohol Depend. 139, 138-144.

Reichel, C. M., Ramsey, L. A., Schwendt, M., McGinty, J. F., See, R. E. (2012) Methamphetamine-induced changes in the object recognition memory circuit. Neuropharmacology 62(2), 1119-1126.

Roussotte, F. F., Rudie, J. D., Smith, L., O'Connor, M. J., Bookheimer, S. Y., Narr, K. L., Sowell, E. (2012) Frontostriatal connectivity in children during working memory and the effects of prenatal methamphetamine, alcohol, and polydrug exposure. Dev. Neurosci. 34(1), 43-57.

Schutová, B., Hrubá, L., Pometlová, M., Deykun, K., Šlamberová, R. (2008) Impact of methamphetamine administered prenatally and in adulthood on cognitive functions of male rats tested in Morris water maze. Prague Med. Rep. 109(1), 62-70.

Schutová, B., Hrubá, L., Pometlová, M., Deykun, K., Šlamberová, R. (2009a) Cognitive functions and drug sensitivity in adult male rats prenatally exposed to methamphetamine. Physiol. Res. 58(5), 741-750.

Schutová, B., Hrubá, L., Pometlová, M., Šlamberová, R. (2009b) Impact of prenatal and acute methamphetamine exposure on behaviour of adult male rats. Prague Med. Rep. 110(1), 67-78.

Schutová, B., Hrubá, L., Rokyta, R., Šlamberová, R. (2013) Gender differences in behavioral changes elicited by prenatal methamphetamine exposure and application of the same drug in adulthood. Dev. Psychobiol. 55(3), 232-242.

Fialová M.; Š́rová J.; Bubeníková-Valešová V.; Šlamberová R. 
Segal, D. S., Kuczenski, R. (2006) Human methamphetamine pharmacokinetics simulated in the rat: Single daily intravenous administration reveals elements of sensitization and tolerance. Neuropsychopharmacology 31(5), 941-955.

Šlamberová, R., Charousová, P., Pometlová, M. (2005) Methamphetamine administration during gestation impairs maternal behavior. Dev. Psychobiol. 46(1), 57-65.

Šlamberová, R., Pometlová, M., Charousová, P. (2006) Postnatal development of rat pups is altered by prenatal methamphetamine exposure. Prog. Neuropsychopharmacol. Biol. Psychiatry 30(1), 82-88.

Šlamberová, R., Pometlová, M., Schutová, B., Hrubá, L., Macúchová, E., Nová, E., Rokyt, R. (2012) Do prenatally methamphetamine-exposed adult male rats display general predisposition to drug abuse in the conditioned place preference test? Physiol. Res. 61, S129-S138 (Suppl. 2).

Šlamberová, R., Macúchová, E., Nohejlová-Deykun, K., Schutová, B., Hrubá, L., Rokyta, R. (2013) Gender differences in the effect of prenatal methamphetamine exposure and challenge dose of other drugs on behavior of adult rats. Physiol. Res. 62, S99-S108 (Suppl. 1).

Vorhees, C.V., Acuff-Smith, K. D. (1990) Prenatal methamphetamine-induced anophthalmia in rats. Neurotoxicol. Teratol. 12(4), 409.

Warburton, E. C., Brown, M.W. (2010) Findings from animals concerning when interactions between perirhinal cortex, hippocampus and medial prefrontal cortex are necessary for recognition memory. Neuropsychologia 48(8), 2262-2272.

Williams, M. T., Blankenmeyer, T. L., Schaefer, T. L., Brown, C. A., Gudelsky, G. A., Vorhees, C.V. (2003) Longterm effects of neonatal methamphetamine exposure in rats on spatial learning in the Barnes maze and on cliff avoidance, corticosterone release, and neurotoxicity in adulthood. Brain Res. Dev. Brain Res. 147(1-2), 163-175.

Wong, C. S., Lee, Y. J., Chiang, Y. C., Fan, L.W., Ho, I. K., Tien, L. T. (2014) Effect of prenatal methadone on reinstated behavioral sensitization induced by methamphetamine in adolescent rats. Behav. Brain Res. 258, 160-165. 